\title{
METEORITES: ROCKS FROM THE OUTER SPACE
}

\author{
SeOng-Jae DoH ${ }^{1}$ and YongJae $\mathrm{YU}^{2}$ \\ ${ }^{1}$ Department of Earth and Environmental Sciences, Korea University, Seoul 136-713, Korea \\ E-mail : sjdoh@korea.ac.kr \\ 2 Department of Geology and Earth Environmental Sciences, Chungnam National University, Daejeon 305-764, \\ Korea \\ E-mail : yongjaeyu@cnu.ac.kr \\ (Received August 20, 2010; Revised September 17, 2010; Accepted October 14, 2010)
}

\begin{abstract}
According to the historical documents and paintings in many civilizations, rocks that fell from the sky fascinated humans as the message from the God or supernaturals. Scientific progress allows humans to recognize these exciting extraterrestrial objects as meteorites. Meteorites contain a wealth of pivotal information regarding formation of the early Solar System. Meteorites also provide broader scientific insights on, for example, the origin of life, interplanetary transfer of life forms, massive depletion of biosphere on Earth, and evolution of lithosphere on Earth-like planetary bodies.
\end{abstract}

Key words : meteorites — chondrites — solar system — Earth — differentiation — core — magnetic field

\section{INTRODUCTION}

Meteorites are rocks from outer space that fall from sky. Nearly all the extraterrestrial solid objects are meteorites except for the lunar rocks collected during the Apollo missions. In Earth and planetary sciences, meteorites are extremely precious in unraveling the chronology of the early Solar System. In fact, meteorites are the only objects that witnessed the early evolution of the Solar System.

It is now common knowledge that the Earth is approximately 4550 million years old. How was this age determined? Our present determination of the age of the Earth came from a study of the radioactive isotopes in meteorites. Radioactive isotopes are inherently unstable. Hence, unstable parent elements spontaneously transform into more stable daughter elements. An interval of time required to transform half of the parent elements into the daughter elements is characterized as half-life. Specific long-lived isotopes whose half-lives are in orders of billion years provide a unique chance to absolutely date the early-formed solid objects in the universe.

As a matter of fact, no terrestrial lithic fragments have been observed to be 4550 million years old. The oldest rock formation on the terrestrial surface is Acasta Gneiss in northwestern Canada, which was initially formed at $4.031 \pm 0.003 \mathrm{Ga}$ (Bowring \& Williams 1999). The oldest mineral zircon from the Acasta Gneiss was dated as $4.203 \pm 0.028 \mathrm{Ga}$ (Lizuka et al. 2006). The oldest single mineral zircon ever found on Earth actually came from the Jackson Hills, Western

Corresponding Author: Y. Yu (yongjaeyu@cnu.ac.kr)
Australia which was dated as $4.404 \pm 0.008 \mathrm{Ga}$ (Wilde et al. 2001; Peck et al. 2001). All the above evidences indicate the existence of a planetary lithosphere on Earth perhaps by as early as $\sim 4400 \mathrm{Ma}$ and without doubt by $\sim 4000$ Ma.

Is there any hope to find much older terrestrial solid objects? A realistic answer would be pessimistic because terrestrial rocks older than $\sim 4400$ Ma will have already weathered out so that they might never be recovered on terrestrial surfaces. Instead, the age of the Earth was inferred as $4.550 \pm 0.070 \mathrm{Ga}$ from the age of troilite fraction in Canyon Diablo iron meteorite (primitive achondrite) (Patterson 1956). The age of the Solar System was confined slightly older than the age of the Earth, determined as 4567.2 $\pm 0.6 \mathrm{Ma}$ from the oldest chondrite age (Amelin et al. 2002). It is already apparent that we use two different types of meteorites (primitive achondrite versus chondrite) to infer the age of the Earth and the Solar System, respectively.

To date, more than 40,000 meteorites have been collected. Among them, only over 1200 meteorites have been observed to fall, while the remaining majorities are find objects. In meteoritic researches, fallen objects are preferred because they are relatively fresh. On the other hand, find objects are collected mostly from places under the world?s most devastating climate conditions (e.g., Antarctica, deserts), and thus are vulnerable to terrestrial contamination and heavy weathering. Therefore scientific investigation of find objects should provide their temporal history since the first landing of meteorites on the Earth by using various isotopic methods.

Most meteorites were found as find objects rather 
(a) Oldest Solid Objects in the Solar System (b) Formation of Planetesimals
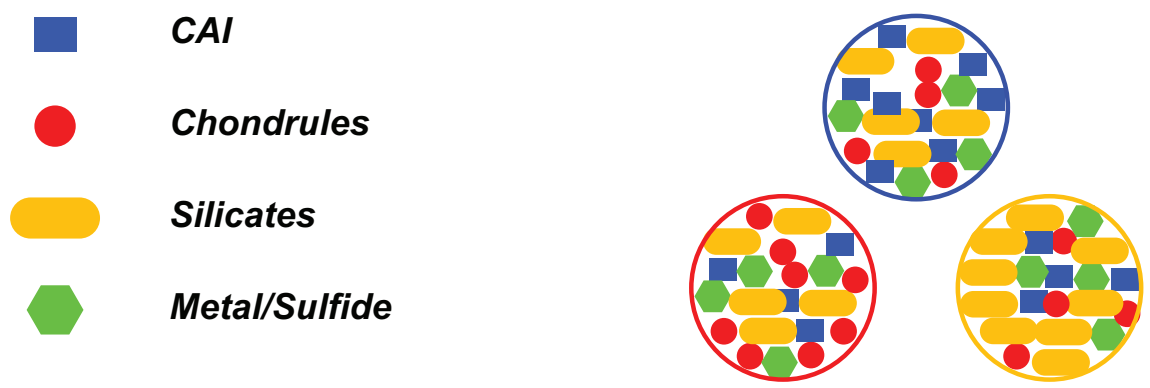

Fig. 1. - Schematic description of the early evolution of the Solar System. (a) Formation of the solid Ca-Al inclusions (CAIs), chondrules, silicates, and metal/sulfide in sequential order. (b) Accretion of CAIs, chondrules, silicates, metals, and sulfides into a planetesimal.

than fallen objects. Thus, a direct correlation between the degree of weathering and the terrestrial residence time has been well established (Jull et al. 1990). That is why terrestrial residence dating $\left({ }^{10} \mathrm{Be},{ }^{14} \mathrm{C},{ }^{36} \mathrm{Cl}\right)$ is necessary to infer the freshness of meteorites (Jull et al. 1990, 1997, 1998; Nishiizumi et al. 1988, 1989, 1991; Vogt et al. 1990). In addition, it is fair to mention that meteorites collected from dry deserts or cold Antarctica tend to be slightly fresher than those collected from humid regions.

\section{CLASSIFICATION OF METEORITES}

\subsection{Accretion of Planetesimals}

Records of the early stage evolution of the Solar System can be unraveled by using the radioactive decay of isotopic elements including the $\mathrm{Pb}-\mathrm{Pb}, \mathrm{Rb}-\mathrm{Sr}, \mathrm{Hf}-\mathrm{W}$, $\mathrm{Sm}-\mathrm{Nd}$ and $\mathrm{K}-\mathrm{Ar}$ system. In particular, the $\mathrm{Pb}-\mathrm{Pb}$ system provides the most precise dating method because it requires to analyze only a single element $\mathrm{Pb}$ while other methods involve analysis of dual elements. The first meaningful solid objects ever produced within the Solar System would be Ca-Al inclusions (CAIs), chondrules, silicates, metal, and sulfide in a sequential order (Fig. 1). Aggregation and accretion of them eventually formed the planetesimals (Fig. 1). Further massive accretion on some of these planetesimals lead them to become the planets of the Solar System (Fig. 2).

The oldest solid object in the Solar System is CAI, formed by the evaporation and condensation process from the gases, although some CAIs showed an evidence of later recrystallization. Refractory minerals in CAI are the first condensates in the Solar System whose age determinations range from 4569 to $4565 \mathrm{Ma}$ (Chen \& Tilton 1976; Chen \& Wasserburg 1981; Ireland et al. 1990). Chondrules are igneous origin, thus they were mainly formed by the crystallization process from liquid droplets to solid spherical objects, although the evaporation and condensation as in CAI contributed to their formation to some degrees. Compared to the CAI, chondrules are believed to be formed under a more oxidizing and rapidly cooled environment. Ages estimated from chondrules range from 4565 Ma to 4562 Ma (Amelin et al. 2002, 2005; Amelin \& Krot 2007; Amelin et al. 2009; Krot et al. 2005a,b; Bouvier et al. 2007). The age difference between the formation of CAIs and chondrules suggests that the CAI and chondrule formation event lasted at least a few million years (Amelin et al. 2002, 2005, 2009). This agrees well with the $\mathrm{Al}-\mathrm{Mg}$ isotopic data, indicating that the formation of chondrule was accompanied by re-melting of preexisting CAIs (Galy et al. 2000; Alexander et al. 2001; Desch \& Connolly 2002; Krot et al. 2005b).

\subsection{General Classification}

Meteorites are labeled on the basis of their spatial information of the sample collecting locations. For instance, the Martian meteorite SAU 008 represents the eighth object among the fallen objects collected from Sayh Al Uhaymir desert, Oman on 26 November, 1999 (Gnos et al. 2002). Another example would be the famous ALH 84001 (Weiss et al. 2000; Antretter et al. 2003), that represents the first find object collected from Allan Hills region in Antarctica during the 1984 expedition. The ALH series requires additional temporal information of the sample collecting years because multi-year scientific expeditions were carried out in Allan Hills regions.

Classification of terrestrial igneous and metamorphic rocks relies on the chemical composition and the crystal textures (Streckeisen 1976, 1979). For instance, terrestrial igneous rocks are classified using the Ternary diagram on which the rock compositions are 

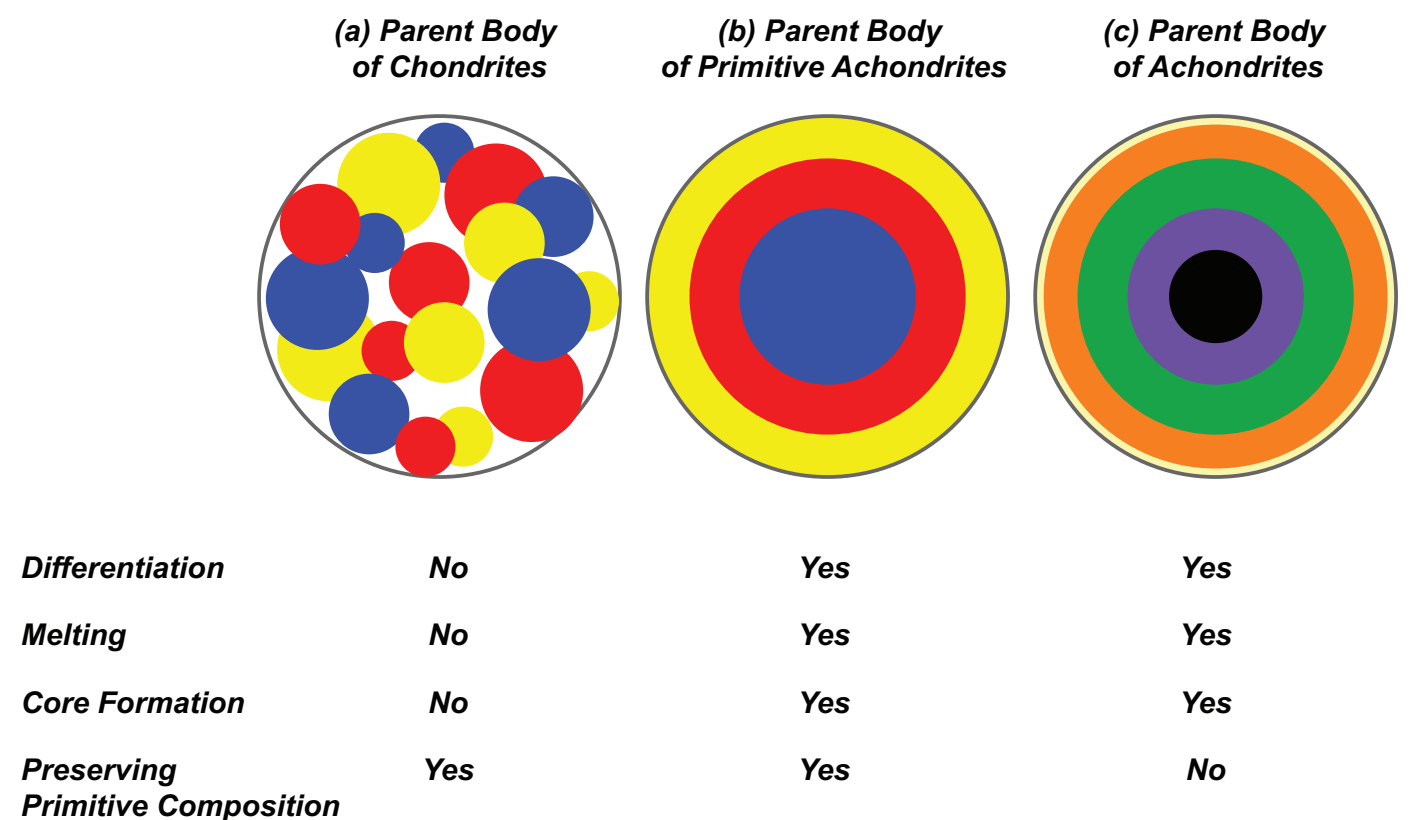

No

Yes

Yes

Yes

Yes

Yes

Yes

Yes

No

Fig. 2.- Schematic illustration of the parent body of (a) Chondrites, (b) Primitive Achondrites, and (c) Achondrites. Primitive compositions represented as blue, red, and yellow are preserved in the parent body of Chondrites and Primitive Achondrites. Parent body of Chondrites lacks the differentiation, melting, or core formation.

represented as a combination of three representative major minerals. Unlike terrestrial cousins, most meteorites are classified on the basis of in-situ similarity between/among the collected lithic pieces. Thus, the certain differences in opinion may persist on the preliminary stage of classification. However, most modern classification systems (Hutchison 2004; Krot et al. 2004) rely on the compositional and isotopic characteristics as well as the petrographic description, following the spirit of Prior (1920) and Mason (1967). According to modern classification, meteorites are divided into three distinctive types of chondrites, achondrites, and primitive achondrites (Fig. 2).

Additional information including the degree of shockpressures and weathering is often added to the conventional meteorite classification scheme. Distinctive shock-pressure indicators such as the presence of metal veinlet, optical precursor of undulatory extinctions for silicates, evidence of partial melting for opaque or silicate phases, and the transformation from plagioclase to maskelynite are used to classify meteorites into S1 (unshocked), S2 (very weakly shocked), S3 (weakly shocked), S4 (moderately shocked), S5 (strongly shocked), and S6 (very strongly shocked) types (Stoffler et al. 1991; Rubin et al. 1997). The weathering grade of meteorite of polished sections were identified as W0 (no visible oxidation), W1 (minor oxidation), W2 (moderate oxidation), W3 (heavy oxidation), W4 (complete oxidation), W5 (onset of alteration), and W6 (evidence of replacement) (Wlotzka 1993).

\subsection{Classification of Chondrites}

Chondrites are undifferentiated meteorites that preserve primordial composition of the primitive Solar System, as evidenced by oxygen isotope data. Parent bodies of chondrites never experienced any melting or differentiation process although an intensive shockinduced metamorphism is inevitable during the accretion process (Fig. 2). Chondrites usually contain abundant sub-micron chondrules that were created from the rapid cooling of hot fluid droplets in space. Chondrules contain olivine $\left((\mathrm{Mg}, \mathrm{Fe})_{2} \mathrm{SiO}_{4}\right)$ and pyroxene $\left(\mathrm{XY}(\mathrm{Si}, \mathrm{Al})_{2} \mathrm{O}_{6}\right.$ where $\mathrm{X}$ and $\mathrm{Y}$ represent different types of cations). Chondrites also possess CAIs that are indisputably the oldest solid objects formed in the Solar System. Other accessory phases in chondrites are Fesulfides (mostly troilite, FeS) and metal-alloy (mostly $\mathrm{Fe}-\mathrm{Ni}$ system with rare $\mathrm{Cr}$ spinel). Of course, clasts of abundant lithic fragments of silicates form the matrix of chondrites.

On the basis of whole rock chemical composition, chondrites are divided into five different major types of C (Carbonaceous), O (Ordinary), E (Enstatite), R (Rumurutti), and $\mathrm{K}$ (Kakagari). Another important classification scheme relies on the petrologic classification as suggested by Van Schmus \& Wood (1967). In general, these two classification schemes are combined. Combined notations of a letter(s) and a number(s) represent the chemical and petrological chondrite types, respectively. For instance, LL6 denotes an LL-type ordinary chondrite with a petrologic degree of 6 .

According to the petrologic description, type 3 rep- 


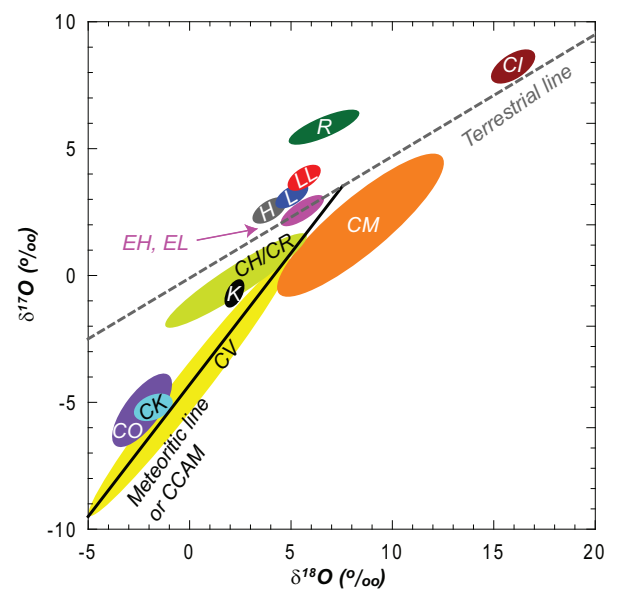

Fig. 3.- Oxygen isotope data for Chondrites (Clayton et al. 1984; Clayton \& Mayeda 1996, 1998). Enrichment of ${ }^{17} \mathrm{O}$ occurs for $\mathrm{H}, \mathrm{L}, \mathrm{LL}$, and $\mathrm{R}$ chondrites. Most $\mathrm{C}$ chondrites showed depletion of ${ }^{17} \mathrm{O}$ except for the CI chondrite. Two distinct slopes represent terrestrial dashed and meteoritic or CCAM (C-Chondrite Anhydrous Mineral) solid lines, respectively.

resents the most pristine material with the least alteration or modification since the chondrite formation. An increase in the value of the petrologic classification (from 4 to 7 ) reflects the increase in the degree of metamorphism and recrystallization. On the contrary, smaller values (from 2 to 1 ) indicate the degree of aqueous alteration. In particular, meteorites with a completely shock-melted type 7 are rare. Subdivision of type 3 ordinary chondrite from 3.0 to 3.9 is available using the thermoluminescene property of feldspar grains resulting from the devitrification of chondrule glass or metamorphic recrystallization (Sears et al. 1980, 1982; Huss et al. 1981).

Oxygen isotopic variation is another important indicator in chondrite analyses (Fig. 3). Intensive oxygen isotopic analyses for various chondrites were compiled by Clayton et al. (1984) and Clayton \& Mayeda (1996, 1998). Oxygen has three isotopes of ${ }^{16} \mathrm{O},{ }^{17} \mathrm{O}$, and ${ }^{18} \mathrm{O}$ in nature. Due to the inherent mass contrast, the isotopic fractionation of ${ }^{16} \mathrm{O}-{ }^{18} \mathrm{O}$ pairs is twice more efficient than that of ${ }^{16} \mathrm{O}-{ }^{17} \mathrm{O}$ pairs. Each type of meteorites display a unique oxygen isotopic ratio when isotopic data from chondrites are plotted (Fig. 3). The $\delta^{17} \mathrm{O}$ and $\delta^{18} \mathrm{O}$ represent the offsetting ratio of ${ }^{17} \mathrm{O}$ and ${ }^{18} \mathrm{O}$ relative to the the ratio of standard mean ocean water in parts per thousand (Fig. 3).

The terrestrial line represents the empirical isotopic fractionation under the terrestrial environment and it has a distinct slope of $\sim 0.5$ (Fig. 3). Such a terrestrial line reflects an efficient differentiation and compositional homogenization from a massive molten body as a result of mass fractionation. Only ordinary and enstatite chondrites have oxygen isotope data range within the narrow limits of terrestrial trend (Fig. 3).
Table 1.

Relative abundance of Chondrites for different compositional (vertical column) versus petrologic (horizontal row) types

\begin{tabular}{|c|c|c|c|c|c|c|c|}
\hline Chondrite type $^{\mathrm{a}}$ & 1 & 2 & 3 & 4 & 5 & 6 & 7 \\
\hline CI & • & & & & & & \\
\hline $\mathrm{CM}$ & 0 & • & & & & & \\
\hline $\mathrm{CR}$ & ○ & • & ○ & & & & \\
\hline $\mathrm{CH}$ & & • & ○ & & & & \\
\hline $\mathrm{CB}$ & & & $\bullet$ & & & & \\
\hline $\mathrm{CV}$ & & ○ & • & & & & \\
\hline $\mathrm{CO}$ & & & • & & & & \\
\hline CK & & & $\circ$ & $\bullet$ & $\circ$ & $\circ$ & \\
\hline $\mathrm{H}$ & & & o & 0 & • & 0 & o \\
\hline $\mathrm{L}$ & & & $\circ$ & $\circ$ & $\circ$ & $\bullet$ & ० \\
\hline LL & & & $\circ$ & $\circ$ & $\circ$ & $\bullet$ & ○ \\
\hline $\mathrm{EH}$ & & & $\bullet$ & o & o & $\circ$ & \\
\hline EL & & & $\circ$ & $\circ$ & $\circ$ & $\bullet$ & \\
\hline $\mathrm{R}$ & & & $\bullet$ & $\circ$ & & & \\
\hline $\mathrm{K}$ & & & • & & & & \\
\hline
\end{tabular}

The $\mathrm{R}$ chondrite appears to be formed in an oxidizing environment, as evidenced by an anomalous enrichment of $\delta^{17} \mathrm{O}$ (Fig. 3).

Most carbonaceous chondrites follow a trend line whose slope is much steeper than that for the terrestrial trend, commonly known as the meteoritic line or the C-Chondrite Anhydrous Mineral (CCAM) mixing line (Fig. 3). Because C chondrites (except for the CI) and $\mathrm{K}$ chondrite fall below the terrestrial reference line, they are attributed to be formed from a reducing environment (Fig. 3). Anomalous deviations from the two major references (both from the terrestrial or CCAM lines) in the oxygen isotopic data (Fig. 3) and low degrees of metamorphism (Table 1) place the CI type as the most primitive chondrites in the Solar System.

\subsection{Chondrites}

C-chondrite was originally termed to emphasize the abundance of carbon, although such historical description is inaccurate in a modern sense. Currently, there exist eight classes of C-type chondrites: CB (Carbonaceous Bencubbin), CH (Carbonaceous ALH 85085), CI (Carbonaceous Ivuna), CK (Carbonaceous Karoonda), CM (Carbonaceous Mighei), CO (Carbonaceous Ornans), CR (Carbonaceous Renazzo), and CV (Car- 
bonaceous Vigarano). Most importantly, C-chondrite shows low $\delta^{17} \mathrm{O}$ except for the CI (Fig. 3).

In terms of meteorite population, O-chondrites are most numerous, because the notation $\mathrm{O}$ represnts ordinary. Distinction between $\mathrm{H}$ and $\mathrm{L}$ relies on the abundance of metallic component. The LL-type chondrites are characterized by the extremely low content of metal constitutes.

E-chondrite is the most chemically reduced lithics, where Fe belongs almost always to the metal-alloy or Fe-sulfide. The E-chondrite is rich in enstatite $\left(\mathrm{MgSiO}_{3}\right)$ rather than olivine which is rich in most other chondrites. The initial nomenclature $\mathrm{E}$ is assigned due to the presence of enstatite.

$\mathrm{R}$-chondrite is similar to $\mathrm{C}$-chondrite in terms of matrix dominance but the oxygen isotope $\left(\delta^{17} \mathrm{O}\right)$ is unexpectedly high compared to the terrestrial counterparts (see Fig. 3). K-chondrite has been recently added as a new type of chondrite. Although $\mathrm{K}$-chondrite is similar to C-chondrite in the oxygen isotopic trend, it is rich in metal, thus similar to $\mathrm{H}$-chondrite in chemical composition.

Table 1 shows the relative abundance of various types of chondrites. Hydrated meteorites (petrologic type 1 and 2) are observed only for CI, CM, CR, and $\mathrm{CH}$, with rare exceptions for the CV. A high-degree of shock pressure is dominating for most ordinary and EL chondrites (Table 1).

\subsection{Achondrites}

Achondrites represent meteorites without a chondrule. Because achondrites were originated from a differentiated planetary body, they appear virtually identical to terrestrial igneous rocks. In fact, all the recognizable igneous textures (that develop as a result of crystallization from the liquid magma) confirm their igneous origin. The most popular achondrite is the HED (Howardites, Eucrites, and Diogenites) series whose isotopic compositions are in agreement with those of the 4 Vesta, indicating that HEDs are probably impact ejecta from the 4 Vesta (McCord et al. 1970; Binzel \& $\mathrm{Xu}$ 2003).

Other types are augrites (rich in Ca-Al-Ti-rich pyroxene), aubrites (rich in enstatite), mesosiderutes (composed of fine-grained igneous matrix, Fe-Ni metal alloy, and Fe-sulfide), pallasite (olivine+metal+troilite), lunar meteorites, and Martian meteorites. More than hundred lunar meteorites have been documented, and their origin has been well-established by comparing the isotopic and mineral compositions between the lunar meteorites and the rock samples directly collected from the lunar surface during the Apollo missions.

More than two dozens of Shergoty-Nakhla-Chassigny (SNC) meteorites are extremely valuable due to the analogy between the Earth and Mars. Unique isotopic signals fossilized in trapped noble gases in shock-melted glass confirmed the Martian origin of SNCs (Nyquist et al. 2001) as they agree well with those directly measured from the Viking Lander (Pepin 1991).

\subsection{Primitive Achondrites}

Five types of primitive achondrites were identified as Acapulcoites (Acapulco), Brachinites (Brachina), Lodranites (Lodran), Ureilites (Novy Ureii), and Winonaites (Winona). Silicate inclusions in IAB and IIICD also belong to this category (Choi et al. 1995).

Primitive achondrites are formed from differentiated parent bodies, as evidenced by melt-generated igneous textures. Yet, the primitive achondrite maintains the primordial chondritic chemical compositions. That is why the age of the Earth can be inferred from the Canyon Diablo iron meteorite (type IAB).

\section{EVOLUTION OF THE SOLAR SYSTEM}

On completing the formation of solid objects within a protoplanetary disk, an accretion process into planetesimals occurs (Fig. 1). Following the aggregation into planetesimals, planetary bodies follow three different paths (Fig. 2). The first path involves aqueous alteration and thermal metamorphism, yet temperatures were not high enough to achieve melting or differentiation (Fig. 2a). Collision (solid-solid reaction) and aqueous alteration (solid-liquid) produce secondary minerals such as carbonates, Fe-oxide, phyllosilicates (Grimm \& McSween 1989; Browninging et al. 1996; Yu et al. 2009). Thermal metamorphism is responsible for the partial destruction of the primary mineral textures and the growth of secondary mineral. On the basis of $\mathrm{Al}-\mathrm{Mg}$ isotopic data, it was found that the metamorphism of chondritic parent body occurred a few million years after the formation of CAIs (Kita et al. 2000; Huss et al. 2001).

The second and third path involves a high temperature melting process where differentiation between silicate and metal occurs (Fig. 2b, 2c). Relatively heavier elements sink down to form a metallic core while the lighter silicates float up, as evidenced by the HfW chronometry (Halliday \& Lee 1999; Halliday 2000, 2004; Kleine et al. 2002, 2005; Yin et al. 2002; Jacobsen 2005).

An evidence of magnetic fields generated externally from the chondritic parent body was preserved in some meteorites (Gattaccecca et al. 2003, 2008; Kletetschka et al. 2003; Weiss et al. 2008; Yu et al. 2009). However, recent studies proposed surprising insights into the possibility of internally generated dynamo on small planetary bodies, suggesting that some meteorites may possess the ancient records of internally generated magnetic fields (Weiss et al. 2010).

In planetary bodies with sizes larger than the asteroids, core formation is pivotal in producing the magnetic field of internal origin (Stevenson 2003). Generation and maintenance of magnetic field of internal origin can effectively protect the solar winds, thus pro- 
vide a chance to fertilize life forms once they are created. In fact, the records of four-billion-year old magnetic field were well preserved in lunar rocks (Lawrence et al. 2008; Garrick-Bethell et al. 2009) and Martian meteorites (Kirschvink et al. 1997; Weiss et al. 2000, 2002; Antretter et al. 2003). As in terrestrial igneous rocks, records of younger volcanism are also preserved in Martian meteorites (Nyquist et al. 2001; Yu \& Gee 2005). On terrestrial crusts, Archean geomagnetic field records were faithfully recovered from the $\sim 2.7 \mathrm{Ga}$ Stillwater Complex, USA (Selkin et al. 2008), 3.2 Ga Pilbara Craton, Australia (Tarduno et al. 2007), and 23.40-3.45 Ga Kaapvaal Craton, South Africa (Tarduno et al. 2009). Such observations indicate that the growth of an inner core developed a persisting terrestrial dynamo for $\sim 3.40-3.45$ Ga. In addition, the presence of strong magnetosphere help to shield a terrestrial atmosphere from the solar wind, shaping the Earth into a more habitable planet by provoking the atmospheric evolution of the Earth.

\section{ACKNOWLEDGMENTS}

Anonymous referees provided insightful comments that significantly improved the manuscript. This work was supported by Mid-career Researcher Program through NRF grant funded by the MEST (No. R012007-000-10517-0).

\section{REFERENCES}

Alexander, C. M. O. D., \& Wang, J. 2001, Iron Isotopes in Chondrules: Implications for the Role of Evaporation during Chondrule Formation, Meteoritics and Planetary Science, 36, 419-428

Amelin, Y., \& Krot, A. 2007, Pb Isotopic Age of the Allende Chondrules, Meteoritics and Planetary Science, 42, 1321-1335

Amelin, Y., Krot, A. N., Hutcheon, I. D., \& Ulyanov, A. A. 2002, Lead Isotopic Ages of Chondrules and Calcium?aluminum-rich inclusions, Science, 297, 1678-1683

Amelin, Y., Ghosh, A., \& Rotenberg, E. 2005, Unraveling the Evolution of Chondrite Parent Asteroids by Precise U-Pb Dating and Thermal Modeling, Geochimica et Cosmochimica Acta, 69, 505-518

Amelin, Y., Connelly, J., Zartman, R. E., Chen, J. H., Gopel, C., \& Neymark, L. A. 2009, Modern U?Pb chrCnometry of Meteorites: Advancing to Higher Time Resolution Reveals New Problems, Geochimica et Cosmochimica Acta, 73, 5212-5223

Antretter, M., Fuller, M., Scott, E., Jackson, M., Moskowitz, B., \& Solheid, P. 2003, Paleomagnetic Record of Martian Meteorite ALH84001, Journal of Geophysical Research, 108(E6), 5049, doi:10.1029/2002JE001979

Binzel, R. P., \& Xu, S. 1993, Chips off of Asteroid 4 Vesta: Evidence for the Parent Body of Basaltic Achondrite Meteorites, Science, 260, 186-191
Bouvier, A., Blichert-Toft, J., Moynier, F., Vervoort, J. D., \& Albarede, F. 2007, Pb-Pb Dating Constraints on the Accretion and Cooling History of Chondrites, Geochimica et Cosmochimica Acta, 71, 1583-1604

Bowring, S. A., \& Williams, I. S. 1999, Priscoan (4.00$4.03 \mathrm{Ga})$ Orthogneisses from Northwestern Canada, Contributions to Mineralogy and Petrology, 134, 316

Browning, L. B., McSween, H. Y., \& Zolensky, M. E. 1996, Correlated Alteration Effects in CM Carbonaceous Chondrites, Geochimica et Cosmochimica Acta, 60, 2621-2633

Chen, J. H., \& Tilton, G. R. 1976, Isotopic Lead Investigations on the Allende Carbonaceous Chondrite, Geochimica et Cosmochimica Acta, 40, 617-634

Chen, J. H., \& Wasserburg, G. J. 1981, The Isotopic Composition of $\mathrm{U}$ and $\mathrm{Pb}$ in Allende Inclusions and Meteoritic Phosphates, Earth and Planetary Science Letters, 52, 1-15

Choi, B. G., Quyang, X., \& Wasson, J. T. 1995, Classification and Origin of IAB and IIICD Iron Meteorites, Geochimica et Cosmochimica Acta, 59, 593612

Clayton, R. N., \& Mayeda, T. K. 1996, Oxygen-Isotope Studies of Achondrites, Geochimica et Cosmochimica Acta, 60, 1999-2018

Clayton, R. N., \& Mayeda, T. K. 1998, Oxygen-Isotope Studies of Carbonaceous Chondrites, Geochimica et Cosmochimica Acta, 63, 2089-2104

Clayton, R. N., Mayeda, T. K., \& Rubin, A. E. 1984, Oxygen-Isotope Compositions of Enstatite Chondrites and Aubrites, Journal of Geophysical Research, 89, C245-C249

Desch, S. J., \& Connolly, H. C. 2002, A Model of the Thermal Processing of Particles in the Solar Nebula Shocks: Application to the cooling rates of chondrules, Meteoritics and Planetary Science, 37, 183207

Galy, A., Young, E. D., Ash, R. D., \& O?Nions, R. K. 2000, The forFormation of Chondrules at High Gas Pressures in the Solar Nebula, Science, 290, 17511753

Garrick-Bethell, I., Weiss, B. P., Shuster, D. L., \& Buz, J. 2009, Early Lunar Magnetism, Science, 323, 356359

Gattaccecca, J., Rochette, P., \& Bourot-Denise, M. 2003, Magnetic Properties of a Freshly Fallen LL Ordinary Chondrite: the Bensour meteorite, Physics of the Earth and Planetary Interiors, 140, 343-358

Gattacceca, J., Rochette, P., Gounelle, M., \& Van Ginneken, M. 2008, Magnetic Anisotropy of HED and Martian Meteorites and Implications for the Crust of Vesta and Mars, Earth and Planetary Science Letters, 270, 280-289 
Gnos, E., Hofmann, B., Franchi, I. A., Al-Kathiri, A., Hauser, M., \& Moser, L. 2002, Sayh al Uhaymir 094: a New Martian Meteorite from the Oman Desert, Meteoritics and Planetary Science, 37, 835-854

Grimm R. E., \& McSween H. Y. 1989, Water and the Thermal Evolution of Carbonaceous Chondrite Parent Bodies, Icarus, 82, 244-280

Halliday, A. N., \& Lee, D-C. 1999, Tungsten Isotopes and the Early Development of the Earth and Moon, Geochimica et Cosmochimica Acta, 63, 4157-4179

Halliday, A. N. 2000, Terrestrial Accretion Rates and the Origin of the Moon, Earth and Planetary Science Letters, 176, 17-30

Halliday, A. N. 2004, Mixing Volatile Loss and Compositional Change during Impact-Driven Accretion of the Earth, Nature, 427, 505-509

Huss, G. R., Keil, K., \& Taylor, G. J. 1981, The Matrices of Unequilibrated Ordinary Chondrites: Implications for the Origin and History of Chondrites, Geochimica et Cosmochimica Acta, 45, 33-51

Huss, G. R., MacPherson, G. J., Wasserburg, G. J., Russell, S. S., \& Srinivasan, G. 2001, Aluminum26 in Calcium-Aluminumrich Inclusions and Chondrules from Unequilibrated Ordinary Chondrites, Meteoritics and Planetary Science, 36, 975-997

Hutchison, R. 2004, Meteorites: A petrologic, Chemical, and Isotopic Synthesis, Cambridge University Press, Cambridge. pp. 506

Ireland, T. R., Compston, W., Williams, I. S., \& Wendt, I. 1990, U-Th-Pb Systematic of Individual Perovskite Grains from the Allende and Murchison Carbonaceous Chondrite, Earth and Planetary Science Letters, 101, 379-387

Jacobsen, S. B. 2005, The Hf-W Isotopic System and the Origin of the Earth and Moon, Annual Reviews of Earth and Planetary Sciences, 33, 531-570

Jull, A. J. T., Wlotzka, F., Palme, H., \& Donahue, D. J. 1990, Distribution of Terrestrial Age and Petrologic Type of Meteorites from Western Libya, Geochimica et Cosmochimica Acta, 54, 2895-2899

Jull, A. J. T., Eastoe, C. J., \& Cloudt, S. 1997, Isotopic Composition of Carbonates in the SNC Meteorites, Alan Hills 84001 and Zagami, Journal of Geophysical Research, 102, 1663-1669

Jull, A. J. T., Courtney, C., Jeffrey, D. A., \& Beck, J. W. 1998, Isotopic Evidence for a Terrestrial Source of Organic Compounds Found in Martian Meteorites, Allan Hills 84001 and Elephant Moraine 79001, Science, 279, 366-368

Kirschvink, J. L., Maine, A. T., \& Vali, H. 1997, Paleomagnetic Evidence of a Low-Temperature Origin of Carbonate in the Martian Meteorite ALH84001, Science, 275, 1629-1633
Kita, N. T., Nagahara, H., Togashi, S., \& Morishita, Y. 2000, A Short Duration of Chondrule Formation in the Solar Nebula: Evidence from 26Al in Semarkona Ferromagnesian Chondrules, Geochimica et Cosmochimica Acta, 64, 3913-3922

Kleine, T., Munker, C., Mezger, K., \& Palme, H. 2002, Rapid Accretion and Early Core Formation on Asteroids and the Terrestrial Planets from Hf-W Chronometry, Nature, 418, 952-955

Kleine, T., Palme, H., Mezger, K., \& Halliday, A. N. 2005, Hf-W Chronometry of Lunar Metals and the Age and Early Differentiation of the Moon, Science, 310, 1671-1674

Kletetschka, G., Kohout, T., \& Wasilewski, P. J. 2003, Magnetic Remanence in the Murchison Meteorite, Meteoritics and Planetary Science, 38, 399-405

Krot, A. N., Amelin, Y., Cassen, P., \& Meibom, A. 2005a, Young Chondrules in CB Chondrites from a Giant Impact in the Early Solar System, Nature, 436, 989-992

Krot, A. N., Yurimoto, H., Hutcheon, I. D., \& MacPherson, G. J. 2005b, Relative Chronology of CAI and Chondrule Formation: Evidence from Chondrule-Bearing Igneous CAIs, Nature, 434, 9981001

Krot, A. N., Keil, K., Goodrich, C. A., Scott, E. R. D., \& Weisberg, M. K. 2004, Classification of Meteorites, In Treatise on Geochemistry, Vol. 1: Meteorites, Comets, and Planets ed. By Davis, A. M., pp. 83-128. Elsevier, Oxford

Lawrence, K., Johnson, C., Tauxe, L., \& Gee, J. S. 2008, Lunar Paleointensity Measurements: Implications for Lunar Magnetic Evolution, Physics of the Earth and Planetary Interiors, 168, 71-87

Lizuka, T., Horie, K., Komiya, T., Maruyama, S., Hirata, T., Hidaka, H., \& Windley, B. F. 2006, 4.2 Ga Zircon Xenocryst in an Acasta Gneiss from Northwestern Canada: Evidence for Early Continental Crust, Geology, 34(4), 245-248

Mason, B. 1967, Meteorites, Meteoritics, 55, 429-455

McCord, T. B., Adams, J. B., \& Johnson, T. V. 1970, Asteroid Vesta: Spectral Reflectivity and Compositional Implications, Science, 168, 1445-1447

Nishiizumi, K., Reedy, R. C., \& Arnold, J. R. 1988, Exposure History of Four Lunar Meteorites, American Scientists, 23, 294-295

Nishiizumi, K., Elmore, D., \& Kubik, P. W. 1989, Update on Terrestrial Ages of Antarctic Meteorites, Earth and Planetary Science Letters, 93, 299-313

Nishiizumi, K., Kohl, C. P., Shoemaker, E. M., Arnold, J. R., Klein, J., Fink, D., \& Middleton, R. 1991, In-Site 10Be-26Al Exposure Ages at Meteor Crater, Arizona, Geochimica et Cosmochimica Acta, 55, 2699-2703 
Nyquist, L. E., Bogard, D. D., Shih, C. Y., Greshake, A., Stoffler, D., \& Eugster, O. 2001, Ages and Geologic Histories of Martian Meteorites, Space Science Review, 96, 105-164

Patterson, C. 1956, Age of Meteorites and the Earth, Geochimica et Cosmochimica Acta, 10, 230-237

Peck, W. H., Valley, J. W., Wilde, S. A., \& Graham, C. M. 2001, Oxygen Isotope Ratios and Rare Earth Elements in 3.3 to 4.4 Ga Zircons; Ion Microprobe Evidence for High Delta 180 Continental Crust and Oceans in the Early Archean, Geochimica et Cosmochimica Acta, 65, 4215-4229

Pepin, R. O. 1991, On the Origin and Evolution of Terrestrial Planet Atmospheres and Meteoritic Volatiles, Icarus, 92, 2-79

Prior, G. T. 1920, The Classification of Meteorites, Mineralogical Magazine, 19, 51-63

Rubin, A. E., Keil, K., \& Scott, E. R. D. 1997, ShockMetamorphism of Enstatite Chondrites, Geochimica et Cosmochimica Acta, 61, 847-858

Sears, D. W. G., Grossman, J. N., Melcher, C. L., Ross, L. M., \& Mills, A. A. 1980, Measuring the Metamorphic History of Unequilibrated Ordinary Chondrites, Nature, 287, 791-795

Sears, D. W. G., Grossman, J. N., \& Melcher, C. L. 1982, Chemical and Physical Studies of Type 3 Chondrites ??I: Metamorphism relRelated Studies of Antarctic and Other Type 3 Ordinary Chondrites, Geochimica et Cosmochimica Acta, 46, 2471-2481

Selkin, P. A., Gee, J. S., Meurer, W. P., \& Hemming, S. R. 2008, Paleointensity Record from the 2.7 Ga Stillwater Complex, Montana, Geochemistry Geophysics Geosystems, 9(12), Q12023, doi:10.1029/2008GC001950

Stevenson, D. J. 2003, Planetary Magnetic Fields, Earth and Planetary Science Letters, 208, 1-11

Stoffler, D., Keil, K., \& Scott, E. R. D. 1991, Shock Metamorphism of Ordinary Chondrites, Geochimica et Cosmochimica Acta, 55, 3845-3867

Streckeisen, A. L. 1976, To Each Plutonic Rock Its Proper Name, Earth Science Review, 12, 1-33

Streckeisen, A. L. 1979, Classification and Nomenclature of Volcanic Rocks, Lamprophyeres, Carbonatites, and Melilitic Rocks: Recommendations and Suggestions of the IUGS Subcommision on the systematics of Igneous Rocks, Geology, 7, 331-335

Tarduno, J. A., Cottrell, R. D., Watkeys, M. K., \& Bauch, D. 2007, Geomagnetic Field Strength 3.2 Billion Years Ago Recorded by Single Silicate Crystals, Nature, 446, 657-660

Tarduno, J. A., Cottrell, R. D., Watkeys, M. K., Hofmann, A., Doubrovine, P. V., Mamajek, E. E., Liu, D., Sibeck, D. G., Neukirch, L. P., \& Usui, Y. 2009, Geodynamo, Solar Wind, and Magnetopause 3.4 to 3.45 Billion Years Ago, Science, 327, 1238-1240
Van Schmus, W. R., \& Wood, J. A. 1967, A ChemicalPetrologic Classification for the Chondritic Meteorites, Geochimica et Cosmochimica Acta, 31, 747765

Vogt, S., Herzog, G. F., \& Reedy, R. C. 1990, Cosmogenic Nucleides in Extraterrestrial Materials, Reviews in Geophysics, 28, 253-275

Weiss, B. P., Kirschvink, J. L., Baudenbacher, F. J., Vali, H., Peters, N. T., Macdonald, F. A., \& Wikswo, J. P. 2000, A Low Temperature Transfer of ALH84001 from Mars to Earth, Science, 290, 791795

Weiss, B. P., Vali, H., Baudenbacher, F. J., Kirschvink, J. L., Stewart, S. T., \& Shuster, D. L. 2002, Records of an Ancient Martian Magnetic Field in ALH84001, Earth and Planetary Science Letters, 201, 449-463

Weiss, B. P., Berdahl, S., Elkins-Tanton, L. T., Stanley, S., Lima, E. A., \& Carporzen, L. 2008, Magnetism on the Angrite Parent Body and the Early Differentiation of Planetesimals, Science, 322, 713-716

Weiss, B. P., Gattacceca, J., Stanley, S., Rochette, P., \& Christensen, U. R. 2010, Paleomagnetic Records of Meteorites and Early Planetesimal Differentiation, Space Science Review, 152, 341-390

Wilde, S. A., Valley, J. W., Peck, W. H., \& Graham, C. M. 2001, Evidence from Detrital Zircons for the Existence of Continental Crust and Oceans on Earth 4.4 Gyr Ago, Nature, 409, 175-178

Wlotzka, F., 1993. A Weathering Scale for the Ordinary Chondrites. Meteoritics, 28, 460

Yin, Q., Jacobsen, S. B., Yamashita, K., BlichertToft, J., Telouk, P., \& Albarede, F. 2002, A Short Timescale for Terrestrial Planet Formation from HfW Chronometry of Meteorites, Nature, 418, 949-952

Yu, Y., \& Gee, J. S. 2005, Spinel in Martian Meteorite SaU 008: Implications for Martian Magnetism, Earth and Planetary Science Letters, 232, 287-294

Yu, Y., Doh S.-J., Kim W., \& Min, K. 2009, Ancient Stable Magnetism of the Richardton H5 Chondrite, Physics of the Earth and Planetary Interiors, 177, $12-18$ 